J. Linguistics 45 (2009), 3I-68. (C) 2009 Cambridge University Press

doi:I0.IOI7/So022226708005513 Printed in the United Kingdom

\title{
Indeterminacy by underspecification ${ }^{1}$
}

\author{
MARY DALR YMPLE \\ Faculty of Linguistics, Philology and Phonetics, University of Oxford \\ TRACY HOLLOWAY KING \\ Powerset, San Francisco \\ LOUISA SADLER \\ Department of Language and Linguistics, University of Essex
}

(Received 28 August 2007; revised 7 October 2008)

We examine the formal encoding of feature indeterminacy, focussing on case indeterminacy as an exemplar of the phenomenon. Forms that are indeterminately specified for the value of a feature can simultaneously satisfy conflicting requirements on that feature and thus are a challenge to constraint-based formalisms which model the compatibility of information carried by linguistic items by combining or integrating that information. Much previous work in constraint-based formalisms has sought to provide an analysis of feature indeterminacy by departing in some way from 'vanilla' assumptions either about feature representations or about how compatibility is checked by integrating information from various sources. In the present contribution we argue instead that a solution to the range of issues posed by feature indeterminacy can be provided in a 'vanilla' feature-based approach which is formally simple, does not postulate special structures or objects in the representation of case or other indeterminate features, and requires no special provision for the analysis of coordination. We view the value of an indeterminate feature such as CASE as a complex and possibly underspecified feature structure. Our approach correctly allows for incremental and monotonic refinement of case requirements in particular contexts. It uses only atomic boolean-valued features and requires no special mechanisms or additional assumptions in the treatment of coordination or other phenomena to handle indeterminacy. Our account covers the behaviour of both indeterminate arguments and indeterminate predicates, that is, predicates placing indeterminate requirements on their arguments.

\section{THE ISSUE}

We examine the formal encoding of feature indeterminacy, focussing on case indeterminacy as an exemplar of the phenomenon. Forms that are

[I] Thanks for feedback and helpful discussion to Anne Abeillé, Doug Arnold, Jim Blevins, Ron Kaplan, Ingo Mittendorf, Irina Nikolaeva, and two anonymous $J L$ reviewers, none of whom, of course, are responsible for anything we have made of their comments. The work 
indeterminately specified for the value of a feature can simultaneously satisfy conflicting requirements on that feature and thus are a challenge to constraint-based formalisms which model the compatibility of information carried by linguistic items by combining or integrating that information (Groos \& van Riemsdijk 1979, Zaenen \& Karttunen I984, Pullum \& Zwicky I986, Ingria I990, Bayer 1996, Dalrymple \& Kaplan 2000, Levy 200I, Levy \& Pollard 200I, Sag 2003, Blevins to appear). Much previous work in constraint-based formalisms has sought to provide an analysis of feature indeterminacy by departing in some way from 'vanilla' assumptions either about feature representations or about how compatibility is checked by integrating information from various sources. In the present contribution we argue instead that a solution to the range of issues posed by feature indeterminacy can in fact be provided in a 'vanilla' feature-based approach which is formally simple, does not postulate special structures or objects in the representation of case or other indeterminate features, and requires no special provision for the analysis of coordination. Our account covers the behaviour of both indeterminate arguments and indeterminate predicates, that is, predicates placing indeterminate requirements on their arguments.

In the remainder of this section, we present the linguistic data which exemplify the indeterminacy problem. Though we focus on case indeterminacy, we see no reason to believe that our approach cannot be extended unproblematically to other indeterminate features as well. Section 2 presents our analysis of case as a complex feature structure and shows how this accounts for the full range of data presented, including the role of modifiers in limiting indeterminacy (what we call the transitivity problem), and the interaction of indeterminacy on both head and argument (what we call the second-order indeterminacy problem). Section 3 presents a comparison with previous proposals and evaluates their ability to account for the full range of phenomena to be analysed. Section 4 concludes.

\section{I.I Case agreement}

We start by reviewing some of the key evidence illustrating the phenomenon of indeterminacy. In a great many languages, dependents are required to agree with their nominal head in a variety of morphosyntactic features, including case. Case agreement between Russian nouns and their adjectival modifiers is shown in (I):

(I) (a) staraja kniga (Russian)

old book

NOM NOM

'(the/a) old book' (nominative adjective, nominative noun)

reported here was carried out with the support of the Arts and Humanities Research Board under project ANio939/APNi7606, which we gratefully acknowledge. 
(b) staruju knigu

old book

ACC ACC

'(the/a) old book' (accusative adjective, accusative noun)

If the case of the adjective does not match that of its head noun, the result is ungrammatical:

(2) (a) *staruju kniga (Russian)

old book

ACC NOM

'(the/a) old book' (accusative adjective, nominative noun)

(b) *staraja knigu

old book

NOM ACC

'(the/a) old book' (nominative adjective, accusative noun)

Case agreement between nouns and their determiners and modifiers is commonly found in the world's languages, as is case government, where a predicate imposes requirements specifying the case of its argument(s).

\section{I.2 Arguments with indeterminate case}

Of course, morphosyntactic features do not always have a unique exponent: paradigmatic syncretism is a widespread phenomenon. For example, German nominal paradigms are highly syncretic, with a single form corresponding to a number of distinct paradigm cells, as shown in the illustrative masculine, feminine and neuter paradigms in (3)-(5).

(3) Masculine

\begin{tabular}{|l|ll|ll|ll|}
\hline MASC & Sing & Plur & Sing & Plur & Sing & Plur \\
\hline NOM & Arm & Arme & Bote & Boten & Papagei & Papageien \\
ACC & Arm & Arme & Boten & Boten & Papagei & Papageien \\
GEN & Armes & Arme & Boten & Boten & Papageis & Papageien \\
DAT & Arm & Armen & Boten & Boten & Papagei & Papageien \\
& \multicolumn{2}{|c|}{ 'arm' } & 'messenger' & 'parrot' \\
\hline
\end{tabular}


(4) Feminine

\begin{tabular}{|l|ll|ll|}
\hline FEM & Sing & Plur & Sing & Plur \\
\hline NOM & Frau & Frauen & Hand & Hände \\
ACC & Frau & Frauen & Hand & Hände \\
GEN & Frau & Frauen & Hand & Hände \\
DAT & Frau & Frauen & Hand & Händen \\
& \multicolumn{2}{|c|}{ 'woman' } & \multicolumn{2}{c}{ 'hand' } \\
\hline
\end{tabular}

(5) Neuter

\begin{tabular}{|l|ll|ll|}
\hline NEUT & Sing & Plur & Sing & Plur \\
\hline NOM & Haus & Häuser & Herz & Herzen \\
ACC & Haus & Häuser & Herz & Herzen \\
GEN & Hauses & Häuser & Herzens & Herzen \\
DAT & Haus & Häusern & Herzen & Herzen \\
& \multicolumn{2}{|c|}{ 'house' } & \multicolumn{2}{c}{ 'heart' } \\
\hline
\end{tabular}

The masculine weak declension plural noun Papageien 'parrots', which shows no case distinctions, can satisfy different case requirements, occurring with verbs that take accusative objects (7a) as well as with those that take dative objects (7b).

(6) Papageien

(German)

parrots

NOM/ACC/DAT/GEN

'parrots' (nominative, accusative, dative, or genitive)

(7) (a) Er findet Papageien. (German)

he finds parrots

$\mathrm{OBJ}=\mathrm{ACC} \mathrm{NOM} / \mathrm{ACC} / \mathrm{DAT} / \mathrm{GEN}$

'He finds parrots.'

(b) Er hilft Papageien.

he helps parrots

$\mathrm{OBJ}=\mathrm{DAT}$ NOM/ACC/DAT/GEN

'He helps parrots.' 


\section{I.2.I Indeterminacy}

Groos \& van Riemsdijk (I979) and Zaenen \& Karttunen (I984) were among the first to point out that syncretic forms can be syntactically indeterminate - that is, simultaneously compatible with more than one requirement for a feature such as case. At least some of the syncretisms illustrated above behave indeterminately, in that the form is compatible with more than one set of morphosyntactic requirements imposed at the same time; such a situation can arise, for example, under coordination. Thus the German form Papageien is able to simultaneously satisfy both ACC and DAT requirements imposed by different verbs, as in (8), showing that it is indeterminate between ACC and DAT.

$$
\begin{aligned}
& \text { Er findet und hilft Papageien. } \\
& \text { he finds and helps parrots } \\
& \text { OBJ=ACC OBJ=DAT NOM/ACC/DAT/GEN } \\
& \text { 'He finds and helps parrots' }
\end{aligned}
$$

The same is true of the feminine plural form Frauen 'woman'.

(9) Er findet und hilft $\quad$ Frauen.
he finds and helps women
OBJ =ACC OBJ=DAT NOM/ACC/DAT/GEN
'He finds and helps women.'

Examples of indeterminate forms are widely found. Dyła (I984) shows that the Polish interrogative pronoun kogo 'who' is indeterminately accusative and genitive, and can be the object of an accusative-taking and a genitivetaking verb at the same time, as in (IO), while a form such as $c o$ 'what', which is indeterminately NOM/ACC, cannot (II).

Kogo Janek lubi a Jerzy nienawidzi? (Polish)
who Janek likes and Jerzy hates
ACC/GEN OBJ=ACC OBJ=GEN
'Who does Janek like and Jerzy hate?'
*Co Janek lubi a Jerzy nienawidzi?
what Janek likes and Jerzy hates
NOM/ACC OBJ=ACC OBJ =GEN
'What does Janek like and Jerzy hate?'

The syntactic effects of indeterminacy can also be observed outside of coordination. A much-discussed instance concerns German free relative constructions, in which the case-matching requirement is not violated just when the relative pronoun is indeterminate between the matrix case and the case required within the relative clause. ${ }^{2}$ The examples in (I2) illustrate the

[2] The facts concerning case agreement in German free relatives are complex, in that case matching is not always a requirement for all speakers. As noted by Dalrymple \& Kaplan 
case-matching requirement: in (I2a), from Groos \& van Riemsdijk (I979), unambiguously nominative wer satisfies the nominative requirements both of the relative clause predicate stark ist and of the matrix verb muss; (I2b) is ungrammatical because wer does not satisfy the dative requirement of geholfen wird.

$$
\begin{aligned}
& \text { (a) Wer nicht stark ist muss klug } \\
& \text { who not strong is must clever bein. (German) } \\
& \text { NOM SUBJ=NOM } \quad \text { SUBJ=NOM } \\
& \text { 'Who isn't strong must be clever.' } \\
& \text { (b) *Wer nicht geholfen wird, muss } \\
& \text { who not hlug sein. } \\
& \text { NOM helped is must clever be } \\
& \text { 'Who isn't helped must be clever.' }
\end{aligned}
$$

In contrast, the relative pronoun was is indeterminately nominative and accusative, and thus can simultaneously satisfy the accusative requirement of gegessen and the nominative requirement of übrig war.

$$
\begin{aligned}
& \text { Ich habe gegessen was übrig war. (German) } \\
& \text { I have eaten what left was } \\
& \mathrm{OBJ}=\mathrm{ACC} \quad \mathrm{NOM} / \mathrm{ACC} \quad \mathrm{SUBJ}=\mathrm{NOM} \\
& \text { 'I ate what was left.' }
\end{aligned}
$$

Similar data can be found in other languages with indeterminate relative pronouns, as seen in the following Russian example from Levy (200I):

(I4) Kogo ja iskal ne bylo doma. (Russian)

$$
\begin{array}{llll}
\text { who I } & \text { sought not was home } \\
\text { ACC/GEN } & \text { OBJ=ACC } & \text { SUBJ=GEN }
\end{array}
$$

'The person who I was looking for wasn't home.'

These data show that any formal treatment of indeterminacy cannot rely on special properties of coordinate structures, but must be general enough to account for indeterminacy in both coordinate and noncoordinate structures.

\section{I.2.2 Ambiguity}

Not all instances of syncretism in the paradigm are susceptible to analysis as indeterminacy. Instead, such forms may exhibit ambiguity: ambiguous forms can obey either one requirement or another, but cannot obey conflicting

(2000), citing a personal communication from Arnold Zwicky, speakers vary as to whether case agreement in the matrix clause is required, and for many speakers, case agreement is required only within the relative clause. See Vogel (200I) for more discussion of case requirements in German free relative clauses. The essential point here, however, is that a sentence containing an apparent violation of a case-matching requirement is unexpectedly grammatical just when an indeterminate form is available. 
requirements at the same time (Zaenen \& Karttunen I984, Pullum \& Zwicky 1986, Ingria 1990, Dalrymple \& Kaplan 2000). Unlike indeterminacy, ambiguity often involves a difference in meaning between the cells of the paradigm (though this is not a necessary property of ambiguous forms). For example, the German pronominal form sie is ambiguous, and can mean either 'she' or 'they', as in (I5).
(a) Sie singt. (German)
she/they sing
SG/PL SG
'She sings.'
(b) Sie singen.
she/they sing
$\mathrm{SG} / \mathrm{PL} \quad \mathrm{PL}$
'They sing.'

It cannot be used indeterminately, as shown in (I6), from Pullum \& Zwicky (1986: 765).

$\begin{array}{llll}* \text { Sie } & \text { singt } & \text { und } & \text { singen. } \\ \text { she/they } & \text { sing } & \text { and } & \text { sing } \\ \text { SG/PL } & \text { SG } & \text { PL }\end{array}$

The English form sheep is likewise ambiguous rather than indeterminate: The sheep is ready, The sheep are there, *The sheep that is ready are there (Ingria 1990). Such structures violate what Zaenen \& Karttunen (1984) call the 'Anti-Pun Ordinance', which forbids the use of an ambiguous form in two senses at once, as if it were actually indeterminate.

Where there is a syncretism in the inflectional paradigm, it is an empirical question whether the forms should be analysed as ambiguous or indeterminate. Here we shall have nothing further to say about whether particular syncretic forms are best analysed as ambiguous or indeterminate (but see Blevins 2000 for some interesting discussion). The data above show that the syncretic forms Frauen and Papageien are at least indeterminate between ACC/DAT. In line with standard practice, and if we have no evidence to the contrary, we will treat them as fully case-indeterminate: that is, we expect that they can satisfy conflicting constraints involving any combination of case values.

The formal analysis of ambiguous forms is straightforward, since an ambiguous form can be treated in just the same way as two separate but morphologically identical forms with different features. In contrast, an adequate analysis of indeterminacy, where a form can simultaneously satisfy conflicting constraints, has proved more elusive in previous work, though a number of different proposals have been made for the syntactic representation of indeterminacy based on the kinds of examples which we have just discussed. We now present some more complicated patterns which must be captured by 
any fully adequate approach to feature indeterminacy and which have proved problematic for some existing approaches. We show in section 2 that the analysis we propose handles these patterns straightforwardly.

\section{I.3 Modifiers resolving indeterminacy}

Although an indeterminate form can simultaneously satisfy conflicting requirements (as in the examples above), modifiers of the same noun must exhibit compatible agreement behaviour (Anette Frank, p.c.; Levy 200I). Any fully adequate approach to the problem of modelling feature indeterminacy will have to take account of this behaviour, which we refer to in what follows as the transitivity problem. It can be seen in (I7) for the Russian noun doč 'daughter', which, like mat' 'mother' (see below), is indeterminately nominative or accusative. Though either nominative or accusative adjectives may modify doč, all of the adjectives must have the same case-marking; intuitively, the addition of a determinate modifier makes the NP determinate for the case feature.

(I7) (a) krasivaja umnaja doč beautiful clever daughter

NOM NOM NOM/ACC

'(a/the) beautiful clever daughter'

(b) krasivuju umnuju doč beautiful clever daughter ACC ACC NOM/ACC

(c) *krasivaja umnuju doč beautiful clever daughter NOM ACC NOM/ACC

(d) *krasivuju umnaja doč beautiful clever daughter ACC NOM NOM/ACC

This pattern is strikingly different from the patterns we have observed for predicates. Examples such as (8) and (9) show that an indeterminate noun can appear as an argument of different predicates which impose incompatible case requirements - in a coordinate structure with an accusativegoverning and a dative-governing predicate in (8), for example. This is not possible for modifiers; a form that is indeterminately nominative and accusative cannot be simultaneously modified by a nominative adjective and an accusative adjective. Instead, modifiers remove or reduce the indeterminacy of the nouns they modify.

Compatibility is also required between modifiers and predicates. A noun that is indeterminately nominative or accusative must take a nominative modifier if the predicate requires nominative case, and an accusative modifier if the predicate requires accusative; other patterns are disallowed, even if the 
noun itself is indeterminate. This is shown in (I8) and (I9). In these examples, the transitive verb ljubit' 'love' takes a nominative subject and an accusative object (as do most Russian verbs). When the noun phrase is a subject, the adjective must be nominative, even if the noun is indeterminate, as in (I8); when the noun phrase is an object, the adjective must be accusative, as in (I9). This holds true regardless of word order. ${ }^{3}$

(I8) (a) Staraja mat' ljubit syna. (Russian)

old mother loves son

NOM NOM/ACC SUBJ $=$ NOM

'The old mother loves (her) son.'

(b) *Staruju mat' ljubit syna.

old mother loves son

ACC $\quad$ NOM $/$ ACC SUBJ $=$ NOM

(19) (a) Syn ljubit staruju mat'. (Russian)

son loves old mother

$\mathrm{OBJ}=\mathrm{ACC}$ ACC NOM/ACC

'The son loves (his) old mother.'

(b) *Syn ljubit staraja mat'.

son loves old mother

$\mathrm{OBJ}=\mathrm{ACC}$ NOM NOM/ACC

Similarly, for the German case-indeterminate noun Papageien, a dativetaking verb requires a determiner (20) or an adjective (2I) to be compatible with the dative requirement.

(20) (a) Er hilft den Papageien.

he helps the parrots

(German)

$\mathrm{OBJ}=\mathrm{DAT} \quad \mathrm{DAT}$ NOM$/ \mathrm{ACC} / \mathrm{DAT} / \mathrm{GEN}$

'He helps the parrots.'

(b) *Er hilft die Papageien.

he helps the parrots

$\mathrm{OBJ}=\mathrm{DAT}$ ACC NOM $/ \mathrm{ACC} / \mathrm{DAT} / \mathrm{GEN}$

(2I) (a) Er hilft alten Papageien.

he helps old parrots

(German)

OBJ $=$ DAT DAT NOM/ACC/DAT/GEN

'He helps old parrots.'

(b) *Er hilft alte Papageien.

he helps old parrots

$\mathrm{OBJ}=\mathrm{DAT}$ ACC NOM/ACC/DAT/GEN

[3] Russian word order encodes discourse functions, not grammatical functions (King 1995). 
In sum, modifiers must be compatible with other modifiers of the same argument, and a modifier of an argument must be compatible with the requirements imposed by the predicate. Conflicting requirements may be imposed on an argument only by different predicates, as in examples (8), (IO), and (I3) in section I.2.

\section{I.4 Indeterminate predicates and second-order indeterminacy}

Just as syncretic nouns may be syntactically indeterminate for the case they express, predicates may be indeterminate in the case requirements that they place on their arguments. ${ }^{4}$ Levy (200I) shows that predicates in Russian can be indeterminate in the case they select for a complement, requiring, for example, objects that may be either genitive or accusative. Simple examples are shown in (22), with more natural examples in (23).

(22) (a) On ždal zvonok. (Russian)

he waited-for call $\mathrm{OBJ}=\mathrm{ACC} / \mathrm{GEN}$ ACC

'He waited for a (phone) call.'

(b) On proždal zvonka naprasno.

he waited-for call in.vain $\mathrm{OBJ}=\mathrm{ACC} / \mathrm{GEN}$ GEN

'He waited in vain for a (phone) call.'

(23) (a) On proždal svoju podrugu Irinu naprasno. (Russian)

he waited-for self's girlfriend Irina in.vain $\mathrm{OBJ}=\mathrm{ACC} / \mathrm{GEN} \quad \mathrm{ACC}$

'He waited for his girlfriend Irina in vain.'

(b) On ždal zvonka ot svoego brata Grigorija.

he waited-for call from self's brother Gregory $\mathrm{OBJ}=\mathrm{ACC} / \mathrm{GEN}$ GEN

'He waited for a call from his brother Gregory.'

That this is not simply an ambiguity is shown by the fact that both cases can be selected at the same time when the complement is a coordinate structure. This is illustrated in (24) from Levy (200I), in which a coordinated object contains a genitive conjunct and an accusative conjunct.

[4] This is a phenomenon which is often discussed in connection with the coordination of unlike categories. For example, an English verb such as remain may select either an AP or an NP complement, and thus is felicitous with a coordinated complement consisting of an AP and an NP argument, as in Lee remained wealthy and a Republican. 
INDETER MINACY BY UNDERSPECIFICATION

$\begin{array}{rlll}\text { (24) Včera ves' den' on proždal } & \text { svoju podrugu Irinu i } \\ \text { yesterday all day he waited-for } & \text { self's } & \text { girlfriend Irina and } \\ & & \text { OBJ }=\text { ACC/GEN } & \text { ACC }\end{array}$

zvonka ot svoego brata Grigorija. (Russian)

call from self's brother Gregory

GEN

'Yesterday he waited all day for his girlfriend Irina and for a call from his brother Gregory.'

Similar patterns are found in Polish. Example (25), from Przepiórkowski (1999), shows that a verb which allows either an ACC or a GEN complement may occur with a coordinate object in which one conjunct is ACC and the other is GEN. Note that the modifiers inside a conjunct must show case agreement with the head noun within their respective conjunct.

(25) Dajcie wina i całą świnię! (Polish)
give $\quad$ wine and whole pig
OBJ=ACC/GEN GEN ACC ACC
'Serve some wine and a whole pig!'

Any treatment of indeterminate predicates must accommodate this ability to impose indeterminate case selection requirements. This is not a marginal phenomenon; Levy (200I) reports that in the languages that he checked showing case alternation for a given grammatical function (including Russian, Polish, Turkish, Tatar and Marathi), coordination of casemismatched conjuncts is always possible.

What is particularly interesting about this type of predicate indeterminacy is that case is itself an indeterminate feature, as we have seen for both Russian and Polish. This leads to what we call the second-order indeterminacy problem, discussed in detail by Levy (200I) and Levy \& Pollard (200I). Theories of indeterminacy must be formulated to allow indeterminate requirements to be placed (for example, by the verb in (24)) on indeterminate features such as CASE (leading to second-order indeterminacy), since it is possible for indeterminate verbs (i.e. those placing indeterminate requirements) to co-occur with nouns which are themselves indeterminate:

(26) On ždal mat' i mal'čika. (Russian)
he waited-for mother and boy
OBJ=ACC/GEN NOM/ACC ACC/GEN
'He waited for his mother and a boy.'

In the next section, we present a new view of feature indeterminacy and indeterminate feature specification which makes use of no formal machinery beyond the simple underspecification of atomic attribute-value pairs, and which not only captures the basic patterns of indeterminacy, but also produces correct results for the transitivity problem and the second-order indeterminacy problem. Section 3 compares our approach to some previous 
theories of indeterminacy in terms of the basic insights they capture, showing that such theories suffer from various problems, particularly with the more complex patterns discussed above.

\section{PROPOSED ANALYSIS}

Since the foundational work of Groos \& van Riemsdijk (1979) and Zaenen \& Karttunen (1984), it has been clear that approaches which rely on specification of simple atomic values for indeterminate features, and on the integration (typically by unification) of information from head and dependent, are problematic. If we assume that a verb like findet 'finds' specifies ACC for its object's case value, and that hilft 'helps' specifies DAT, we obtain a case clash between the ACC specification and the DAT specification in an example like (27), leading to the incorrect prediction that the example is unacceptable:

$$
\begin{aligned}
& \text { Er findet und hilft Papageien. } \\
& \text { he finds and helps parrots } \\
& \text { OBJ=ACC OBJ=DAT ACC=DAT feature clash } \\
& \text { 'He finds and helps parrots.' }
\end{aligned}
$$

(For more discussion of this point, see (among others) Ingria I990, Johnson \& Bayer 1995, Bayer 1996, Dalrymple \& Kaplan 2000, and Levy 200I.) This obviously correct observation has led to proposals which postulate a wide variety of additional formal devices, or departures from otherwise standard assumptions, to accommodate various facets of the indeterminacy problem.

Our proposal, in contrast, handles the data discussed so far, including the transitivity problem and the second-order indeterminacy problem, without introducing new structures or operations and without departing from standard assumptions about feature specification. That is, our analysis maintains the 'vanilla' assumption that compatibility between requirements is checked by stating equalities that integrate information from different sources. The essence of our approach to the indeterminacy problem is that we view the value of CASE as a complex feature structure. The basic intuition is that the lexical specification of CASE associated with an indeterminate element is more general - in other words, less specified - than that of a determinate element. ${ }^{5}$ Case specifications associated with modifiers and predicates must be compatible, and may restrict the indeterminacy. On our view:

- The value of the CASE attribute is a feature structure which allows specification and differentiation of each (core) case by means of a separate (boolean-valued) attribute: NOM, ACC, DAT, and so forth. A negative value indicates the inability of a form to satisfy the corresponding case requirement, while a positive value indicates that the form can satisfy

[5] Blevins (2005) makes a proposal for the treatment of word-class features in cases of categorial indeterminacy which is similar in some respects to this proposal. 
the requirement. Indeterminate forms can satisfy more case requirements than determinate forms; thus, indeterminate forms contain a smaller number of negative specifications and allow a larger number of positive specifications for case.

- Nouns and their modifiers specify negative values for the cases they do not express, and specify or are compatible with positive values for the cases they do express. As we will see, it is this which captures the intuition that modifiers restrict or remove the indeterminacy of the nouns they modify.

- Verbs (and other predicates) specify positive values for the case(s) they require to be realized. Since indeterminate forms can have positive values for more than one case feature, this allows indeterminate forms to satisfy conflicting requirements imposed by different predicates.

For concreteness, we present our analysis in terms of the f(unctional)-structures of Lexical Functional Grammar (LFG; Kaplan \& Bresnan 1982, Bresnan 200I, Dalrymple 200I), although we believe that the basic insights of the analysis can be incorporated into any feature-based theory which permits underspecification of feature structures. LFG f-structures are attribute-value matrices that record syntactic information such as grammatical functions and, of import here, case requirements. For clarity of presentation, we depart from standard LFG notation and representation in two respects: first, we use a slightly simplified version of the standard LFG notation for feature structure constraints; second, where the value of an attribute is unspecified, we often represent case attributes graphically with unspecified values in the f-structure, rather than omitting the attribute altogether.

To illustrate our approach, we consider the case system of German, which has four cases (nominative, accusative, dative, genitive). The CASE structure of a fully determinate accusative noun is shown in (28a), and (28b) shows a fully determinate dative noun.

(28) (a) Determinate accusative case

$$
\left[\operatorname{CASE}\left[\begin{array}{cc}
\mathrm{NOM} & - \\
\mathrm{ACC} & + \\
\mathrm{GEN} & - \\
\mathrm{DAT} & -
\end{array}\right]\right]
$$

(b) Determinate dative case

$$
\left[\operatorname{CASE}\left[\begin{array}{cc}
\mathrm{NOM} & - \\
\text { ACC } & - \\
\text { GEN } & - \\
\text { DAT } & +
\end{array}\right]\right]
$$


A verb requiring a dative OBJ, as in (29), combines with a dative argument (28b), but not an accusative argument (28a).

(29) Er hilft ihm/*ihn.

(German)

he helps him.DAT/him.ACC

'He helps him.'

The case specification associated with the verb hilft is given in (30):

(30) hilft: OBJ CASE DAT $=+$

The combination of the dative object ihm with hilft is shown in (3I), where the positive DAT specification imposed by the verb is compatible with the intrinsic case specifications of the object:

$$
\begin{aligned}
& \text { hilft ihm } \\
& \text { DAT }
\end{aligned}
$$

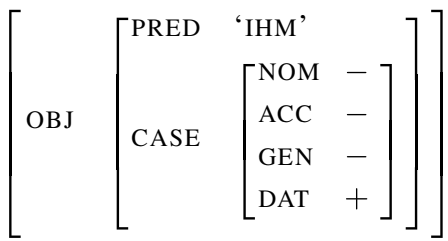

In contrast, the accusative object ihn cannot combine with hilft, since a clash in case specifications results: the positive DAT specification imposed by hilft clashes with the negative DAT specification of ihn, since ihn cannot express dative case:

(32) *hilft ihn

$\mathrm{ACC}$

Ill-formed f-structure (hilft's DAT + clashes with ihn's DAT -)

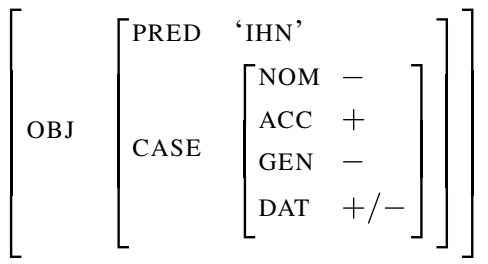

\section{I Indeterminacy}

This representation (using atomic boolean-valued features) allows a straightforward treatment of indeterminacy. Indeterminate nouns simply have fewer negative case specifications than fully specified nouns, thereby ruling out fewer possibilities for satisfying case requirements. An indeterminate noun is 
negatively specified for any cases it does not express. It also requires a positive specification for at least one of the cases that the noun can express, since any use of a noun must express some case; this is crucial in preventing the imposition of incompatible and unsatisfiable case requirements on indeterminate nouns.

Consider again the MASC noun Papagei 'parrot', which is generally considered to have the paradigm shown in table (33). ${ }^{6}$

\begin{tabular}{|lll|}
\hline MASC & Sing & Plur \\
\hline NOM & Papagei & Papageien \\
ACC & Papagei & Papageien \\
GEN & Papageis & Papageien \\
DAT & Papagei & Papageien \\
\hline
\end{tabular}

Since the plural form is fully case-indeterminate, the case specification for Papageien is as given in (34); this can be read as requiring that within the CASE structure, the value for NOM, ACC, DAT, or GEN must be.$+^{7}$ In other words, Papageien is a cased form: it must express some case or other, but there are no restrictions on which case it expresses. This permits the form to occur in contexts compatible with a positive specification of one or more of the cases, and does not impose any negative case specifications that would rule out case possibilities for the form.

$$
\text { Papageien; } \operatorname{CASE}\{\mathrm{NOM}|\operatorname{ACC}| \operatorname{DAT} \mid \operatorname{GEN}\}=+
$$

Combining Papageien with a verb requiring an accusative object in an example like (7a), repeated as (35a), results in a case specification like (35b) for the object, the result of combining the information from the verb and that

[6] Note, however, that for some speakers this particular noun may also follow a so-called weak paradigm in the singular, giving Papageien as alternative ACC/DAT/GEN singular form.

[7] The expression in (34) uses functional uncertainty (Kaplan \& Zaenen 1989) to encode a disjunction over attributes. Our analysis abstracts away from a technical issue: there are four f-structure solutions to this description, since Papageien is compatible with a positive specification for any of the four case features NOM, ACC, GEN, and DAT. If the predicate does not restrict the case of the noun, Papageien would be treated as four ways ambiguous. This is, of course, undesirable, and can be fixed by building in the assumption that the value for each CASE feature defaults to + : this means that nouns are maximally indeterminate in each instance of their use (positively specified for as many case values as possible), taking into account constraints imposed by the predicate and modifiers. The treatment of feature defaults in LFG is straightforward; see Dalrymple et al. (2004) for discussion. 
from the noun in the same feature structure. In example $(7 b)$, repeated as (36a), the verb takes a dative object, and this results in the case specification in $(36 b){ }^{8}$
(a) Er findet Papageien.
he finds parrots
(German)
$\mathrm{OBJ}=\mathrm{ACC} \quad \mathrm{NOM} / \mathrm{ACC} / \mathrm{GEN} / \mathrm{DAT}$
'He finds parrots.'

(b)

$$
\left[\text { OBJ }\left[\begin{array}{ll}
\text { PRED } & \text { 'PARROTS' } \\
\text { CASE } & {\left[\begin{array}{l}
\text { NOM } \\
\text { ACC }+ \\
\text { GEN } \\
\text { DAT }
\end{array}\right]}
\end{array}\right]\right]
$$

(36) (a) Er hilft Papageien.

he helps parrots

$$
\text { OBJ }=\text { DAT NOM/ACC/GEN/DAT }
$$

'He helps parrots.'

(b)

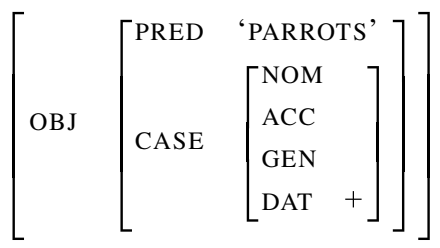

For sentences like (8) (repeated in (37a)), with coordinated accusative and dative verbs, no clash results from simultaneously specifying positive values for both ACC and DAT on an indeterminate noun like Papageien. The specification for the verbs in (37a) is shown in (37b).
(a) Er findet und hilft Papageien.
he finds and helps parrots
$\mathrm{OBJ}=\mathrm{ACC} \quad \mathrm{OBJ}=\mathrm{DAT} \quad \mathrm{NOM} / \mathrm{ACC} / \mathrm{GEN} / \mathrm{DAT}$
(German)
'He finds and helps parrots.'
(b) findet: OBJ CASE $\mathrm{ACC}=+$
hilft: OBJ CASE DAT $=+$

The relevant portion of the analysis of (37a) is given in (38). Coordinate structures in LFG are treated as sets (Kaplan \& Maxwell I988); here, the

[8] As noted above, we include attributes with unspecified values in the f-structure representation, to make the difference between fully specified and underspecified forms more apparent. 
coordinated verbs findet and hilft give rise to a coordinate structure in which the functional structure of the object Papageien is shared between the two verbs. This is indicated by the line connecting the OBJ of the verb findet 'finds' to the OBJ of hilft 'helps'. Since Papageien is the object of both verbs, it must satisfy the requirements imposed by both; this is possible because it allows both ACC and DAT to be positively specified.

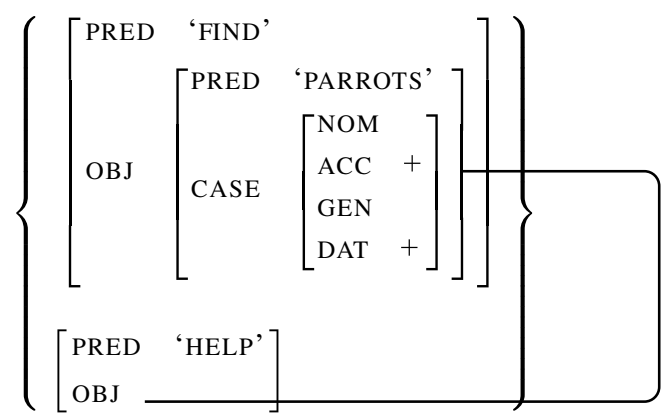

The case selection specifications introduced by the verbs are (both) imposed directly on the (shared) object within the coordinate structure. The treatment of indeterminacy involves simply and solely the use of the underspecified case structure.

A partially indeterminate form such as Arme 'arms.NOM/ACC/GEN' or Männer ' $\mathrm{men} . \mathrm{NOM} / \mathrm{ACC} / \mathrm{GEN}$ ' is specified as in (39). The positive specification for NOM, ACC, or GEN permits the form to appear as an argument of a predicate that requires nominative, accusative, or genitive case, while the negative specification for DAT precludes its occurrence with verbs requiring DAT case or with DAT modifiers. We discuss modification and case requirements in the next section.

$$
\begin{aligned}
\text { Männer: } & \text { CASE } \mathrm{DAT}=- \\
& \text { CASE }\{\text { NOM } \mid \text { ACC } \mid \operatorname{GEN}\}=+
\end{aligned}
$$

The approach also deals unproblematically with cases of NP coordination in which one conjunct is indeterminate, as in (40). The DAT + case specification associated with the verb is satisfied (independently) by each conjunct; no clash results in either conjunct.

(40) Er hilft Kindern und Frauen.

(German)

he helps children and women

$$
\text { OBJ = DAT DAT NOM/ACC/DAT/GEN }
$$

'He helps children and women.'

Importantly, no special provision is needed for coordination. In the analysis of German free relatives, the indeterminate relative pronoun was can 
simultaneously fill nominative and accusative case requirements, as shown in (I3), repeated here as (4I):

Ich habe gegessen was übrig $\quad \begin{array}{ll}\text { war. (German) } \\ \text { I have eaten what left } & \text { was } \\ \text { OBJ }=\text { ACC NOM/ACC } & \text { SUBJ=NOM }\end{array}$
'I ate what was left.'

The case specifications for was are given in (42):

$$
\begin{aligned}
\text { was: } & \text { CASE } \text { DAT }=- \\
& \text { CASE } \text { GEN }=- \\
& \text { CASE }\{\text { NOM } \mid \text { ACC }\}=+
\end{aligned}
$$

These specifications are compatible with positive requirements for either NOM or ACC (though not with DAT or GEN specifications), and so this form can appear as the subject of a verb that requires nominative case and a the object of a verb that requires accusative case. As above, the result is that both ACC and NOM are positively specified.

\section{(43) übrig: SUBJ CASE NOM $=+$ gegessen: OBJ CASE ACC $=+$}

In sum, by representing the value of the morphosyntactic CASE feature as a feature structure, and using underspecification, our analysis ensures that positive specifications can be successfully imposed on indeterminate arguments by different predicates, whether in a coordinate structure, a relative clause construction, or any other construction where an argument must satisfy the case requirements of more than one predicate.

\subsection{Transitivity}

We have seen that modifiers behave differently from predicates in that they reduce or remove the indeterminacy of the nouns they modify. Intuitively, this is because modifiers also realize features of the head. This is straightforwardly and naturally captured in our analysis: modifiers specify negative requirements for case features with which they are not compatible, and in so doing may restrict the case options of the noun that they modify. An unambiguously dative adjectival modifier like German alten 'old' is specified as follows, where (ADJ $\in$ ) refers to the structure of the noun being modified (we use the set membership symbol here because each modifier is a member of the set of modifiers at f-structure). ${ }^{9}$

[9] We treat adjectival modifiers as directly constraining the intrinsic CASE features of the nominal they modify, though an alternative account using case matching between nominal and modifier is also possible. Nothing hinges on this distinction in the present context: we could equally well adopt a concordial view under which both modifiers and head have case 
(44) alten: (ADJ $\in$ ) CASE $\mathrm{NOM}=-$

$(\mathrm{ADJ} \in)$ CASE $\mathrm{ACC}=-$

$(\mathrm{ADJ} \in)$ CASE $\mathrm{GEN}=-$

The presence of a modifier can render indeterminate nouns fully (or partially) determinate. Though the indeterminate noun Papageien can appear where accusative and dative requirements are simultaneously imposed, it cannot be modified by an unambiguously accusative or dative modifier in such a situation, since such modifiers restrict the case possibilities of the noun in a way which is incompatible with the requirements of the predicates. An unambiguously dative modifier like alten 'old' imposes a negative specification for ACC, clashing with the positive specification for ACC of the accusative-taking verb findet in (45):
(a) *Er findet und hilft alten Papageien. he finds and helps old parrots $\mathrm{OBJ}=\mathrm{ACC} \quad \mathrm{OBJ}=\mathrm{DAT} \quad \mathrm{DAT} \quad \mathrm{NOM} / \mathrm{ACC} / \mathrm{DAT} / \mathrm{GEN}$
(German)

'He finds and helps old parrots.'

(b) Ill-formed f-structure (findet's ACC + clashes with alten's ACC -)

$$
\left[\begin{array}{ll}
\text { PRED } & \text { 'PARROTS' } \\
\text { CASE } & {\left[\begin{array}{ll}
\text { NOM } & - \\
\text { ACC } & +/- \\
\text { GEN } & - \\
\text { DAT } & +
\end{array}\right]}
\end{array}\right]
$$

And a modifier that is indeterminately nominative/accusative but not dative, such as alte 'old', imposes a negative specification for DAT; this specification is incompatible with the requirements of hilft:

(46) (a) *Er findet und hilft alte lapageien.
he finds and helps old parrots
OBJ=ACC OBJ=DAT NOM/ACC NOM/ACC/DAT/GEN
'He finds and helps old parrots.'
(b) alte: (ADJ $\in$ ) CASE GEN $=-$
$($ ADJ $\in$ ) CASE DAT $=-$

feature structures whose values are identified. The expression in (44) uses inside-out functional uncertainty to refer to the functional structure containing the modifier. 
(c) Ill-formed f-structure (hilft's DAT + clashes with alte's DAT -)

$$
\left[\begin{array}{ll}
\text { PRED } & \text { 'PARROTS' } \\
\text { CASE } & {\left[\begin{array}{l}
\text { NOM } \\
\text { ACC }+ \\
\text { GEN }- \\
\text { DAT }+/-
\end{array}\right]}
\end{array}\right]
$$

In contrast, modification by a suitably indeterminate modifier is acceptable, since no incompatible specifications are imposed. The indeclinable adjective rosa 'pink' is fully indeterminate, and imposes no additional case restrictions:

(47) rosa: [no case restrictions]

The noun Papageien can be modified by rosa and still satisfy simultaneous accusative and dative requirements, since its case realisation possibilities are not restricted by the modifier.

(48) (a) Er findet und hilft rosa Papageien.

he finds and helps pink parrots

$$
\mathrm{OBJ}=\mathrm{ACC} \quad \mathrm{OBJ}=\mathrm{DAT} \quad \mathrm{NOM} / \mathrm{ACC} / \mathrm{DAT} / \mathrm{GEN}
$$

'He finds and helps pink parrots.'

(b) $\left[\begin{array}{ll}\text { PRED } & \text { 'PARROTS' } \\ \text { CASE } & {\left[\begin{array}{ll}\text { NOM } & \\ \text { ACC } & + \\ \text { GEN } & \\ \text { DAT } & +\end{array}\right]}\end{array}\right]$

Modifiers that are incompatible with the case expression possibilities of the noun are also disallowed. The lexical entry given in (39) for the noun Männer 'men', repeated in (48), requires DAT to have a negative value:

(49) Männer: CASE DAT $=-$

CASE $\{$ NOM $|\operatorname{ACC}| \mathrm{GEN}\}=+$

This prevents Männer from combining with an unambiguously dative modifier, such as the plural adjective alten 'old', whose lexical entry was given in (44). This is because a clash in the value for DAT would result; Männer is negatively specified for DAT, while alten requires a positive specification for DAT.

However, Männer can combine with the genitive plural alter, whose case specification is given in (50a), resulting in the unambiguously genitive structure shown in (5ob). 
(50) (a) alter: CASE NOM $=-$

CASE $\mathrm{ACC}=-$

CASE DAT $=-$

(b)

$$
\left[\begin{array}{lll}
\text { PRED } & \text { 'MEN' } \\
\text { CASE } & {\left[\begin{array}{ll}
\text { NOM } & - \\
\text { ACC } & - \\
\text { GEN } & + \\
\text { DAT } & -
\end{array}\right]}
\end{array}\right]
$$

\subsection{Indeterminate predicates and second-order indeterminacy}

We now turn to the treatment of indeterminate requirements imposed by predicates, exemplified above with data from Polish and Russian. We assume six core cases for Russian (nominative, accusative, genitive, dative, instrumental, and prepositional). ${ }^{10}$ In (5I), repeated from (24), the noun podrogu 'girlfriend' is accusative, while the noun zvonka 'call' is genitive:

(5I) Včera ves' den' on proždal svoju podrugu Irinu yesterday all day he waited-for self's girlfriend Irina

$$
\mathrm{OBJ}=\mathrm{ACC} / \mathrm{GEN} \quad \mathrm{ACC}
$$

i zvonka ot svoego brata Grigorija.

(Russian)

and call from self's brother Gregory GEN

'Yesterday he waited all day for his girlfriend Irina and for a call from his brother Gregory.'

(52) (a) podrugu: CASE NOM $=-$

CASE $\mathrm{ACC}=+$

CASE GEN $=-$

CASE DAT $=-$

CASE INST $=-$

CASE PREP $=-$

(b) zVonka: CASE NOM $=-$

CASE $\mathrm{ACC}=-$

CASE GEN $=+$

CASE DAT $=-$

CASE INST $=-$

CASE $\mathrm{PREP}=-$

[Io] In general, Russian case paradigms are not as syncretic as the German ones, although most paradigms have at least one syncretic form. In addition, Russian syncretism is less likely to involve putative natural classes of paradigm cells, witness e.g. the collapse of the genitive, dative, and locative singular in the third declension. 
The Russian verb proždat' 'wait for' imposes indeterminate CASE requirements, requiring an object which is either genitive or accusative:

$$
\text { proždat': OBJ CASE }\{\text { ACC } \mid \mathrm{GEN}\}=+
$$

Since the object is a coordinate structure, modelled as a set of f-structures, any specification of a feature for the coordinate structure amounts to specifying that feature for each conjunct (member of the set of f-structures). ${ }^{11}$ In particular, any determinate or indeterminate case requirement placed on the coordinate structure as a whole is required to hold of each conjunct. In this example, each conjunct must satisfy the (indeterminate) requirement that its CASE be either GEN or ACC. This indeterminate case specification permits the verb to occur with a GEN complement, an ACC complement, or a coordination with mixed case, as in (5I), whose structure is shown in (54).

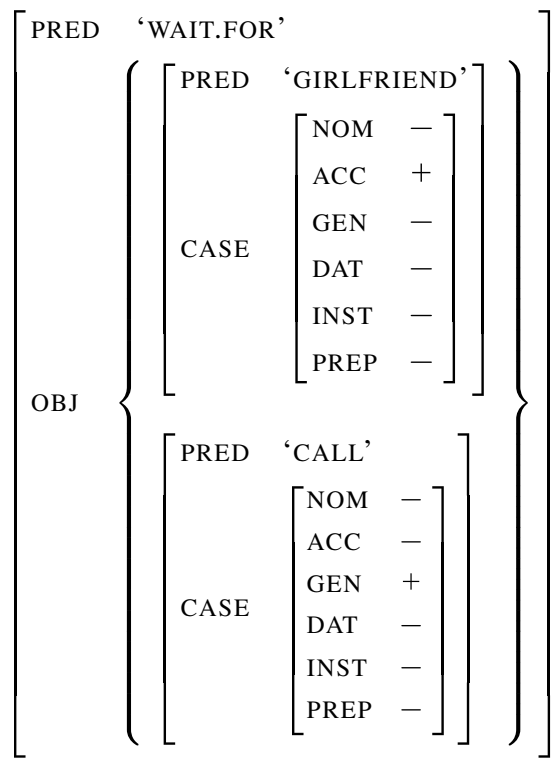

Crucially, the indeterminate requirements imposed by the verb can be resolved differently in each conjunct, as is standard with functional uncertainty expressions and coordination (Kaplan \& Maxwell I988, Dalrymple 200I: chapter I4). This allows the verb to govern coordinated objects with different case features, as long as each conjunct is compatible with a positive specification for either ACC or GEN. Again, nothing special needs to be added in order to ensure that conjuncts of a coordinated argument may independently

[II] This is the normal case: features which behave in this way are distributive. A small set of features behave differently and define properties of the set itself (such as CONJ-FORM and the INDEX features for person and number). These features are non-distributive. See Dalrymple \& Kaplan (2000), King \& Dalrymple (2004). 
satisfy the indeterminate case requirements associated with the verbal predicate, since this falls out from the standard treatment of coordination in LFG.

Levy (200I) has observed that independent resolution of indeterminate case requirements is found quite generally in languages with case alternation for the governed argument, as our analysis predicts. However, if a language is, unusually, subject to an additional case-matching requirement in this circumstance, this can be treated as an additional fact about nominal coordination which may be simply expressed in the relevant coordination rule by requiring all of the conjuncts to express the same case.

Within each conjunct, of course, values must be consistent (in line with transitivity), as is evident in the Polish example (25), repeated as (55), where the modifier of świnie 'pig' is required to bear accusative case. This follows from our treatment of case features of modifiers: case specifications for the adjective cala 'whole' must be compatible with the specifications of the accusative noun it modifies, świnie.

$$
\begin{aligned}
& \text { Dajcie wina i cała świnię! (Polish) } \\
& \text { give wine and whole pig } \\
& \text { GEN ACC ACC }
\end{aligned}
$$

'Serve some wine and a whole pig!'

Finally, it follows from our analysis that the nouns themselves may be indeterminate and at the same time subject to an indeterminate case selection by the verbal predicate: all that is required is that each noun is consistent with one of the values specified by the indeterminate predicate.

In sum, our approach to feature indeterminacy assumes that CASE is a possibly underspecified structured value, with different cases distinguished by different attributes. This permits a clean and intuitive approach to case indeterminacy: indeterminate elements simply express fewer constraints over the CASE feature, and predicates and modifiers interact to provide further specification of CASE, often narrowing down the indeterminacy. It follows that such constraints must be compatible, solving the transitivity problem. Indeterminate behaviour (e.g. in free relatives and under coordination) follows with no further stipulations. Indeterminate predicates are associated with a (limited) functional uncertainty in the statement of their case requirements, accounting for the second-order indeterminacy problem and capturing the case alternation facts under coordination.

\section{Previous proposals}

The combination of feature indeterminacy with a range of syntactic constructions in which an indeterminate element can be subject to conflicting requirements poses a particular challenge to constraint-based syntactic formalisms, and has generated a range of proposals for changes or extensions 
to the basic information-combining machinery of such formalisms, or the introduction of additional representational devices. In the following, we situate our own proposal within the array of responses that the phenomenon of indeterminacy has provoked. We discuss several alternative formal proposals for the treatment of indeterminacy, highlighting problems of coverage where these occur, and drawing attention to the additional machinery adduced in the solution of the indeterminacy problem. We concentrate attention on these particular proposals because they are representative of the range of proposals that have previously been made, and we omit discussion of some other influential proposals for the treatment of feature indeterminacy, e.g. Johnson \& Bayer (I995) and Bayer (I996), which have been shown to be untenable or otherwise unattractive in other work (Bayer I996, Dalrymple \& Kaplan 2000, Sag 2003), or which are not substantially different from the proposals we discuss in this section.

Section 3.I discusses the proposal of Dalrymple \& Kaplan (2000); though this proposal is simple and formally appealing, it does not provide an adequate treatment of either the transitivity problem or the second-order indeterminacy problem. Section 3.2 discusses two proposals by Ingria (1990), the first of which does not adequately address the transitivity problem. The other proposal is very similar (though not identical) to our approach; Ingria dismisses this proposal on the basis of objections which we believe are illfounded. Section 3.3 discusses several approaches within Head-driven Phrase Structure Grammar (HPSG), showing that they are either unwieldy or move HPSG substantially closer to LFG in its modelling assumptions.

Other authors have also proposed to treat the value of the CASE feature as a feature structure. Neidle (1982) proposes a feature structure representation of the Russian case system, based on work by Jakobson (I958), which encodes commonalities across the various case forms in a compact way, though she does not apply the representation to an account of indeterminacy. Blevins (to appear) uses a structured approach to case based on notions of markedness in his discussion of the treatment of indeterminacy, encoding six cases by means of boolean values of three features, again based on Jakobson (I958). ${ }^{12}$ Our proposal differs from Blevins's and Neidle's proposal for CASE decomposition in that we posit a separate feature for each case possibility in the language, though it may well be that a more compact and illuminating representation can be given while preserving the insights of our

[I2] Note that the compact structured case representation does not in itself make any additional contribution to solving the indeterminacy problem: the account in Blevins (to appear) must also replace the use of equality to combine information from various (potentially clashing) sources with the widespread use of subsumption. In the case of Blevins's example, given in (Io) above, lubi 'like' which takes an accusative object and nienawidzi 'hate' which takes a genitive object define conflicting values for the QuA case feature ( - and + respectively). Thus these issues concerning the precise nature of the feature structure representation of case are at least partly orthogonal to the main concern of the current paper. 
approach. As pointed out by an anonymous reviewer, it has proven difficult to define general principles of structural organisation in feature decompositions of the Jakobsonian kind; the Russian syncretisms that motivated the original Jakobson proposal have been shown by Baerman et al. (2005: chapter 3) to have 'limited application beyond Russian'. We leave for future work the issue of the extent to which a more compact and linguistically wellmotivated representation of CASE can be given, perhaps using notions of markedness.

\section{I Dalrymple \& Kaplan 2000}

Dalrymple \& Kaplan (2000) use sets (rather than atoms) as values for indeterminate features such as CASE, and they propose that the value of the CASE feature of a noun is the set of all cases with which it is compatible. Predicates check for case compatibility by checking whether the case they require is a member of the case set of the argument. The treatment is similar in spirit to the present proposal: members of the CASE set in Dalrymple \& Kaplan's proposal correspond to the positively specified case attributes in our theory, and elements that do not appear in a CASE set are the negatively specified attributes. However, that proposal does not allow modifiers to contribute additional constraints to reduce or remove indeterminacy in nouns, and thus it does not provide a solution to the transitivity problem.

On the Dalrymple \& Kaplan approach, the indeterminately accusative/ dative noun Papageien has the case value $\{$ ACC, DAT (again, assuming for simplicity that the indeterminacy here is limited to these two cases). The verb findet requires ACC to be a member of the case set of its object, and hilft requires DAT; in example (8), repeated in (56), both of these requirements are satisfied.

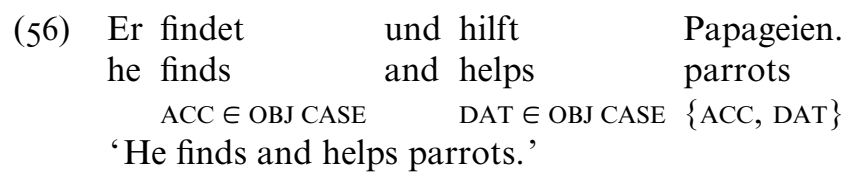

In contrast, example (57) is unacceptable; the unambiguously dative form wem has the case specification $\{\mathrm{DAT}\}$. This set does not contain ACC as a member, and does not satisfy the case requirements imposed by the verb nehme.

$$
\begin{aligned}
& \text { *Ich nehme, wem du vertraust. } \\
& \text { I take } \quad \text { who you trust } \\
& \text { ACC } \in \text { OBJ CASE }\{\text { DAT }\} \text { DAT } \in \text { OBJ CASE } \\
& \text { 'I take who(ever) you trust.' }
\end{aligned}
$$

This treatment works well for simple cases of indeterminacy, but it does not provide an account of the transitivity problem, nor does it provide a 
straightforward solution to the second-order indeterminacy problem, as we now show. ${ }^{13}$

\section{I.I Transitivity}

The inability of the Dalrymple \& Kaplan approach to account for transitivity of agreement requirements is the most serious problem for their analysis. They explicitly acknowledge that their account does not extend to examples exhibiting transitivity requirements (Dalrymple \& Kaplan 2000: 777 f.), and they do not consider how the simple examples we examined above could be treated within their approach. Example (I8), repeated in (58), illustrates the problem. Example (58a) is correctly predicted to be grammatical, since the case requirements of both the adjective and the verb are satisfied by the case set of the indeterminate noun mat'. However, example (58b) is also incorrectly predicted to be grammatical, since here too all requirements are satisfied.

$\begin{array}{llll}\text { (a) Staraja mat' } & \text { ljubit } & \text { syna. } & \text { (Russian) } \\ \text { old } & \text { mother loves } & \text { son } & \\ \text { NOM } \in \text { CASE } & \{\text { NOM,ACC } & \text { NOM } \in \text { SUBJ CASE } & \\ \text { 'The old mother loves (her) son.' } & \\ \text { (b) *Staruju mat' } & \text { ljubit } & \text { syna. } & \text { son } \\ \text { old } & \text { mother } & \text { loves } & \text { son } \\ \text { ACC } \in \text { CASE } & \{\text { NOM,ACC } & \text { NOM } \in \text { SUBJ CASE }\end{array}$

The problem is that requirements imposed by the modifier do not narrow down the possibilities for case expression of the noun (the modifier cannot remove members from the CASE set), and so there is no way to rule out unacceptable examples such as (58b). In contrast, our approach allows underspecification of the CASE properties of the noun and further instantiation of these properties by the modifier, which allows for a treatment of the transitivity problem.

[13] Blevins (to appear) presents an approach to the basic indeterminacy data which in some sense builds on this approach. The set-based representations are replaced by compact feature structure representations (based on notions of markedness). His account relies crucially on replacing the statement of equalities by the use of subsumption for controlling the flow of information from a daughter's f-structure to a mother's f-structure to ensure that incompatible case requirements of predicates do not come into conflict. In this approach, the predicates do not share an object (which would then be subject to conflicting case requirements), but rather the object of each predicate is subsumed by the feature structure corresponding to the indeterminate noun. It is possible that an account using subsumption rather than equality could be made to work in LFG for all the transitivity and second-order indeterminacy data. However, moving to an inherently directional approach in which information is required to flow 'upwards' is a radical departure from standard assumptions, and is a signficant cost to pay to avoid conflict between case requirements (moreover, as Levy (200I) notes, it may run into trouble with indeterminacy in free relatives). 


\section{I.2 Second-order indeterminacy}

Dalrymple \& Kaplan discuss examples of indeterminate predicates as well as indeterminate verbs, but do not discuss cases in which a predicate places indeterminate requirements on a feature that is itself indeterminate, as found in Russian and Polish ((24) and (25) respectively). Given that nouns in these languages can be indeterminately specified for case, Dalrymple \& Kaplan must analyze the CASE feature as set-valued. There is no easy way on their approach to express indeterminate requirements on indeterminate features. One way to do this within the spirit of the set-based account would be to allow the verb to specify the set of the possible cases of its object. The requirement would then be that the set of cases which the object can express would have to overlap with the set of cases required by the predicate; formally, this would require a non-null intersection between the predicate's case set and the object's case set. Though it is not possible to impose this requirement within the standard formal assumptions of LFG, other featurebased theories might be enriched or modified to impose such a requirement. Nevertheless, the fact that additional formal devices must be brought to bear to solve the second-order indeterminacy problem is another strike against their analysis.

\subsection{Ingria 1990}

Ingria (I990) claims that the standard formal assumptions of feature-based theories like LFG are inadequate to deal with indeterminacy and the patterns we have examined so far, and proposes to enrich them with a new way of handling disjunctive feature values - that is, this approach introduces an additional mechanism for checking feature compatibility. On his approach, the value specified by a noun for an indeterminate feature like CASE may be a disjunction. Disjunctive feature values are checked not with equality but by means of a nondistinctness check, which is represented as $\approx$ rather than $=$. On Ingria's analysis, the value of the CASE feature for an indeterminately nominative and accusative noun like German Papageien 'parrots' is (at least) a disjunction ACC $\vee$ DAT over the two possible values ACC and DAT. Predicates check to see if their case requirements are compatible with (or, in Ingria's terms, nondistinct from) the case values of their arguments, but do not replace or instantiate the disjunction with a specific value:

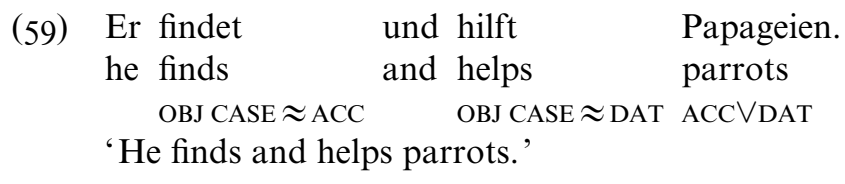

In example (59), the requirements imposed by each verb are met, since the value ACC $\vee$ DAT is nondistinct from both ACC and DAT. In contrast, example 
(6o) is unacceptable: the unambiguously dative form wem has case DAT, and this value is distinct from the case requirements imposed by the verb nehme.

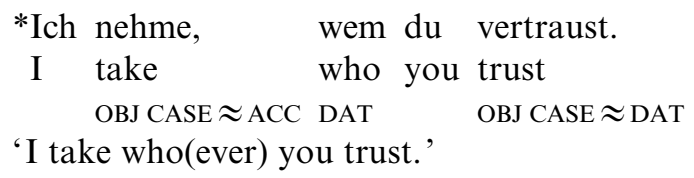

This treatment is somewhat heavy-handed in that it introduces a new formal mechanism to deal with indeterminacy, but it works well for determinate nouns and for simple cases of indeterminacy. However, it faces problems in dealing with more complex cases, as we now show.

\subsection{Transitivity}

As noted by Blevins (to appear), the Ingria analysis is designed to circumvent the undesirable effects of transitivity of equality imposed by standard analyses of feature agreement using equality: his analysis does not produce a feature clash between ACC and DAT in examples like (27), and so correctly predicts that (27) is acceptable. However, as shown above, transitivity is in fact desirable in some cases. The requirements imposed by a modifier must be compatible with the requirements of other modifiers and with the requirements of the predicate. Ingria's analysis fails to capture this, since his analysis imposes a nondistinctness check by the adjectival modifier which does not constrain or narrow the possibilities for case expression of the noun; modifier requirements and verbal requirements are checked independently, and neither can affect the other. The case requirements in (6ra) are correctly met, but Ingria's analysis incorrectly predicts that in (I8), repeated as (6I), the case requirements in (6Ib) are met as well, and therefore that (6Ib) is as acceptable as (6ra):

(6I) old mother loves son
CASE $\approx$ NOM NOM $\bigvee A C C$ SUBJ CASE $\approx$ NOM
'The old mother loves (her) son.'
(a) Staraja mat' ljubit syna. (Russian)
(b) *Staruju mat' ljubit syna. old mother loves son
$\mathrm{CASE} \approx \mathrm{ACC}$ NOM $\vee \mathrm{ACC}$ SUBJ CASE $\approx \mathrm{NOM}$

\subsubsection{Feature structures and the analysis of Hungarian}

Ingria (1990) discusses an alternative analysis of German case, citing a personal communication from Andy Haas, which is very close to our proposal: the value of the CASE feature is a feature structure whose attributes are the 
case possibilities NOM, ACC, and so forth, and forms are positively specified for the cases they express. One important difference that distinguishes the Haas/Ingria proposal from ours is that indeterminate forms are not underspecified, but are given a positive specification for all the case possibilities with which they are compatible. For example, according to the Haas/Ingria analysis, the indeterminately accusative/dative noun Papageien is specified with both ACC + and DAT + (assuming for simplicity that the indeterminacy is just between these two values). If indeterminate nouns are fully specified with positive or negative values for all of their case possibilities, it is not possible for modifiers to narrow down the case expression possibilities of the nouns they modify. However, we have seen in the previous section that underspecification is desirable; although the unmodified noun mat' 'mother' is indeterminately nominative and accusative, the modified phrase staruju mat' 'old.ACC mother' is fully specified as accusative, and can be used only in accusative environments. Thus, an analysis like ours, involving underspecification, fares better in dealing with the transitivity problem than the Haas/Ingria proposal.

In fact Ingria dismisses this alternative Haas/Ingria analysis on the basis of patterns of definiteness agreement in Hungarian, to which we now turn; all Hungarian data cited below are from Ingria (1990). Hungarian verbs are marked as definite or indefinite, depending on the definiteness of their objects:

(62) (a) Akart egy könyvet. (Hungarian) he.wanted a book

INDEF INDEF

'He wanted a book.'

(b) *Akarta egy könyvet.

he.wanted a book

DEF INDEF

'He wanted a book.'

(c) Akarta a könyvet.

he.wanted the book

DEF DEF

'He wanted the book.'

Sentential complements behave as definite objects:

(63) János akarta, hogy elhozzak egy könyvet. (Hungarian)

John wanted that I.bring a book

DEF DEF

'John wanted me to bring a book.'

The verb must also agree in definiteness with a topicalized or displaced constituent (for example, a relative pronoun), which may be an argument of a subordinate clause. Because verbs must appear in the definite form when 
they have a sentential complement, any constituent which is displaced from a sentential complement must itself be definite in order to meet the definiteness agreement requirements of the verb:

(64) (a) Ez az a könyv amelyiket akarta hogy elhozzam. this that the book which he.wanted that I.bring DEF DEF DEF DEF DEF

'This is the book which he wanted me to bring.'

(b) *Egy könyv amit akarta hogy elhozzak. a book which he wanted that I.bring INDEF INDEF DEF DEF INDEF 'a book which he wanted me to bring'

(Hungarian)

Crucial for Ingria's argument is the existence of verb forms that allow either definite or indefinite constituents to be displaced from sentential complements:

(65) Egy könyv akartam, hogy elhozzon. (Hungarian)

a book I.wanted that he.bring

INDEF INDEF/DEF DEF DEF

'It was a book that I wanted him to bring.'

Ingria's analysis of these verbs is that they are indeterminately indefinite and definite, and can thus license a definite sentential complement and an indefinite topicalized constituent at the same time. We find this analysis reasonable.

Since the Haas/Ingria analysis involves positive specification of all of the values that an indeterminate form can express, their analysis of Hungarian necessitates the following claims:

(66) Hungarian, Haas/Ingria analysis

(a) Indeterminately definite/indefinite verbs must be positively specified for both definiteness and indefiniteness: $\left[\begin{array}{ll}\mathrm{DEF}+ \\ \mathrm{INDEF}+\end{array}\right]$

(b) Definite and indefinite relative pronouns must be partially unspecified:

- Definite relative pronoun amlyiket: $[\mathrm{DEF}+]$

- Indefinite relative pronoun amit: [INDEF +]

These two claims together entail that when a definite or indefinite pronoun appears with an indeterminate verb, it 'becomes' indeterminate for definiteness, which is the wrong result: definite pronouns are unambiguously definite even when they appear with indeterminate verbs, and similarly for indefinite pronouns. 
However, there is a further alternative analysis of the Hungarian facts which does not suffer from these problems: the pronouns can be analysed as unambiguously definite or indefinite, not as underspecified, and the indeterminate verbs can be treated as completely unspecified for definiteness. If the verb places no constraints on topicalized argument, either a definite or an indefinite pronoun is correctly allowed.

(67) Hungarian, our alternative analysis

(a) Indeterminately definite/indefinite verbs are unspecified for definiteness and indefiniteness.

(b) Definite and indefinite relative pronouns are fully specified:

- Definite relative pronoun amlyiket: $\left[\begin{array}{ll}\mathrm{DEF}^{+} \\ \mathrm{INDEF} & -\end{array}\right]$

- Indefinite relative pronoun amit: $\left[\begin{array}{ll}\mathrm{DEF}^{2} & - \\ \mathrm{INDEF} & +\end{array}\right]$

These assumptions account adequately for all of the data that Ingria presents. Thus, the Ingria objections to a feature structure-based account of indeterminacy are not fatal for the type of approach we pursue here. Furthermore, Ingria's approach is undesirable in two respects: it complicates the standard assumptions of feature-based theories by adding a new formal operation, a nondistinctness check, to handle indeterminacy; and, even in doing so, it fails to provide an account of the transitivity problem.

\subsection{HPSG accounts}

The problem of indeterminacy and neutralisation has received a good deal of attention within HPSG, because it poses a particular challenge to the modelling assumptions that feature structures are (i) totally well-typed (that is, are specified for all features that are appropriate for that type of feature structure) and (ii) sort-resolved (that is, assigned a maximal type (one which has no subtypes)). Two types of approach can be distinguished. One strand of work, represented by Daniels (200I), Levy (200I) and Levy \& Pollard (200I), maintains the standard modelling assumptions of HPSG, requiring feature structures to be totally well-typed and sort-resolved. Levy (200I) in particular is notable for addressing in some considerable detail the issues and problems raised here, and most especially the problem of indeterminate requirements placed by predicates over indeterminate features (the secondorder indeterminacy problem). The other strand, represented by Sag (2003), adopts an approach which allows underspecification, and thus entails giving up these standard assumptions. The guiding intuition behind all of these HPSG analyses of indeterminacy is that of Johnson \& Bayer (1995) and Bayer (1996), introducing conjunctive and disjunctive types in the modelling of feature indeterminacy (syncretism) and feature neutralisation (e.g. in the coordination of unlikes). 


\subsection{Levy/Pollard}

We take Levy (200I) and Levy \& Pollard (200I) as representative of the first approach, and follow the presentation of the more accessible Levy paper; Levy \& Pollard (200I) state that the approach of Daniels is 'essentially equivalent' to their own proposal. This analysis maintains the standard HPSG requirement of sort-resolution, meaning that the value of every attribute must be a maximal (leaf) type. In other words, all structures, including indeterminate forms and coordinate structures, must have fully specified CASE values. This is at odds with the intuition embodied by our analysis: that information can be partial or underspecified. Levy introduces 'double sets', in which feature values are modelled as sets of sets, organised into a lattice separate from and additional to the normal type system of HPSG, and uses lattice-theoretic orderings and set-theoretic operations such as intersection to constrain CASE values.

A noun that is indeterminate between NOM and ACC case has as its case value the set $\{\{\mathrm{NOM}\},\{\mathrm{ACC}\}\}$. Predicates specify a lower bound for the case of their arguments on this lattice, with the effect that a predicate is satisfied by an argument that has exactly the case it requires, or an indeterminate case that includes the required case as one of its possibilities. For example, a predicate requiring an ACC argument can take as its argument an indeterminately nominative/accusative noun with case $\{\{\mathrm{NOM}\},\{\mathrm{ACC}\}\}$. This makes the correct predictions for simple cases of indeterminacy, as well as for noncoordinate constructions such as the German free relative construction illustrated in (I3). In such cases, an indeterminate argument is acceptable just so long as it satisfies the case requirements of each predicate.

To solve the transitivity problem, Levy's treatment of modification appeals to intersection: the CASE value for a modified noun is obtained by intersecting the CASE of the noun and the CASE of the modifier. This means that the case of an indeterminate noun can be made more determinate, or completely determinate, by its modifier, and produces the right results for examples like (I8)-(I9).

The second-order indeterminacy problem is addressed by a special rule for coordinate phrases which computes a case value for the coordinate structure using an operation of double intersection defined on double sets. For example, a coordinate phrase with an ACC conjunct and a GEN conjunct has as its case value the set $\{\{\mathrm{ACC}, \mathrm{GEN}\}\} .{ }^{14}$ A coordinate phrase with this specification cannot be the argument of a predicate which requires an ACC predicate, since such a predicate is not compatible with the GEN specification contributed by the GEN conjunct. Only an appropriately indeterminate

[I4] This representation is crucially different from the representation of an indeterminately accusative/genitive noun, which would be represented as $\{\{\mathrm{ACC}\},\{\mathrm{GEN}\}\}$. 
predicate can take a coordinate structure as its argument if the conjuncts of the coordinate phrase express different cases. The introduction of this special rule for coordinate phrases enables a treatment of coordinated nouns with different cases as arguments of indeterminate predicates, as in example (24).

The Levy/Pollard approach does in fact successfully handle the data presented above, including the transitivity problem and the second-order indeterminacy problem. However, other HPSG researchers have criticised it for being overly complex; Sag (2003: 288) observes that the Levy/Pollard proposal and related proposals 'have imposed new hierarchies on maximal types or else have introduced considerable complexity into existing type hierarchies'. And indeed, we believe that allowing underspecification, as our approach does, leads to a simpler treatment of indeterminacy, for two reasons. First, indeterminate nouns can be associated with very general descriptions of the CASE feature which can then be enriched by constraints associated with modifiers and predicates; no new types or type hierarchies are required. Second, the treatment of coordination in LFG together with the standard assumption that CASE is a distributive feature provides a straightforward treatment of indeterminate predicates that does not require the coordinate structure to bear a special disjunctive type, computed on the basis of the CASE of the conjuncts; instead, case constraints imposed by a predicate are applied directly to the conjuncts.

\subsubsection{Sag}

Sag (2003) proposes an account of the indeterminacy and transitivity data which in some respects resembles ours, in that - unlike the Levy/Pollard approach - it appeals to underspecification, though it differs in appealing to type subsumption rather than equality. Starting from the observation that the requirement of sort-resolvedness presents a real difficulty to getting an elegant and uncomplicated treatment of these data in HPSG, Sag proposes to abandon this foundational requirement. ${ }^{15}$

The abandonment of the requirement for sort-resolvedness means that while all the appropriate features for a feature structure must be specified, the values no longer have to be maximal in the type system. Like Levy's analysis, the basic idea is that predicates impose a lower bound on the CASE value of their arguments, while arguments either fix their type or provide an upper bound on their own CASE value. This means that an argument can take on a range of CASE values within a construction, provided that any value that

[I5] Although this represents a radical change to the formal foundations of the theory, Sag argues that no undesirable consequences ensue from this change. 
the argument takes is compatible with its own and its predicate's lexical specifications. ${ }^{16}$

When a predicate specifies a lower bound on the case of its argument, it specifies the most general type that the case may have; the specification in the lexical entry for findet, for example, which takes an ACC object, is compatible with an ACC noun or any indeterminate form which is compatible with ACC. In the following hierarchy of types we follow Sag in representing the lower (more general) types higher in the following diagram showing the hierarchy of types. (68) is the type hierachy for the case system of German (Sag 2003: 278). The most specific types, at the bottom of the hierarchy, are those that coordinated predicates with different case requirements call for.

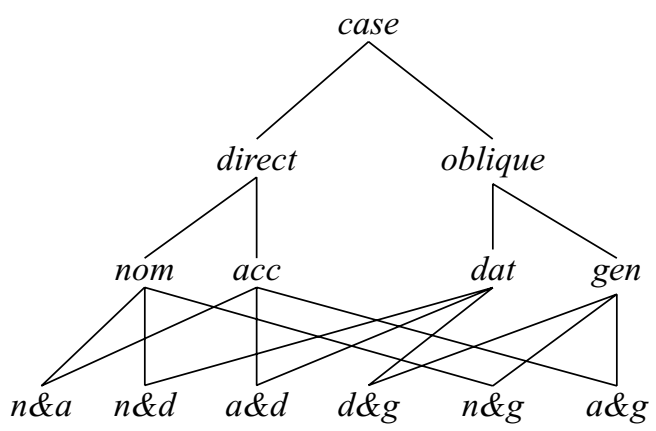

Nouns also use type subsumption: Frauen 'women' which can resolve to any case, has no case specification at all, and a fully determinate form such as the dative Kindern 'children', specifies that dat is the upper bound on its case: this ensures that it is incompatible with (for example) more specified subtypes acc\&dat, dat\&gen and so forth, though it is compatible with a more general oblique requirement. Intuitively, verbs place requirements which are compatible downwards in the hierarchy (hence compatible with more

[I6] To accomplish this, Sag considers a redefinition of 'root' signs so that the most general satisfier is chosen:

(i) A feature structure $F$ corresponds to a stand-alone utterance with respect to a grammar $G$ just in case $F$ satisfies:

I. all constraints of $G$

2. is an unslashed sign which has VFORM fin

3. and there is no $F^{\prime}$ more general than $F$ that also satisfies $\mathrm{I}$ and 2 .

This means that 'we need only consider a small space of alternative types in order to determine whether the assigned type is the most general one compatible with the relevant constraints. This is all that needs to be considered in order to determine well-formedness. Thus the notion of "most general satisfier" of a set of constraints that I am appealing to here seems unproblematic.' (Sag 2003: 28I). This move is necessary precisely because of the abandonment of sort-resolvedness, and is quite reminiscent of the role of the minimal solution in LFG (Kaplan \& Bresnan 1982). 
informative types) and nouns place requirements which are compatible upwards in the hierarchy (and so compatible with more general requirements).

Like the Levy/Pollard proposal, and unlike our account, Sag's treatment requires a special treatment for coordination. Much of the work of controlling information flow must be explicitly stated in the coordination schema, in order to allow just the right amount of movement up and down the relevant type hierarchy for case. ${ }^{17}$ Sag solves the transitivity problem by requiring identity of CASE values to be imposed NP-internally. Thus, an example like (69) is ruled out because the case restrictions imposed by the determiner are incompatible with the requirement (imposed by the predicate) for CASE to be greater than (more specific than) or equal to dat.

(69) Er hilft *die Frauen.

he helps the.ACC women

'He helps the women.'

Indeterminate requirements on predicates are treated in a similar way to the Levy/Pollard approach. In example (25), repeated as (70), the indeterminate predicate dajcie sets the more general type $a c c \vee$ gen as the lower bound for its NP argument. The nouns fix the type of their case as GEN and ACC respectively: $:^{18}$

[17] Sag's schema for coordination (excepting NP coordination) for German is as shown in (ii) (Sag 2003: 277), where boxed numbers indicate structure sharing:

(i)

$$
\left[\begin{array}{l}
\mathrm{HD}=0 \\
\mathrm{VAL}=1
\end{array}\right] \rightarrow\left[\begin{array}{l}
\mathrm{HD}=0 \\
\mathrm{VAL}=1
\end{array}\right] \cdots\left[\begin{array}{l}
\mathrm{HD}=0 \\
\mathrm{VAL}=1
\end{array}\right] \mathrm{CONJ}\left[\begin{array}{l}
\mathrm{HD}=0 \\
\mathrm{VAL}=1
\end{array}\right]
$$

For an example such as (9), repeated here as (ii), the result of identifying the valence of the daughters in the coordinate structure is to drive the case of the comp to be acc\&dat, which can be satisfied by the indeterminate noun Frauen but not by an unambiguously dative or accusative complement.

(ii) Er findet und hilft Frauen. he finds and helps women 'He finds and helps women.'

[18] In fact, it is not completely clear that the correct result is obtained for examples of this sort. The NP coordination rule (Sag 2003: 28I) identifies the values of the CASE features of the conjuncts, while allowing for type resolution of PER values.

(i)

$$
\left[\begin{array}{l}
\mathrm{NP} \\
\mathrm{NUM}=p l \\
\mathrm{PER}=0 \\
\mathrm{CAT}=\mathrm{C}
\end{array}\right] \rightarrow\left[\begin{array}{l}
\mathrm{NP} \\
\mathrm{PER}=1 \\
\mathrm{CAT}=\mathrm{C}
\end{array}\right] \ldots\left[\begin{array}{l}
\mathrm{NP} \\
\mathrm{PER}=\mathrm{N}-1 \\
\mathrm{CAT}=\mathrm{C}
\end{array}\right] \text { CONJ }\left[\begin{array}{l}
\mathrm{NP} \\
\mathrm{PER}=\mathrm{N} \\
\mathrm{CAT}=\mathrm{C}
\end{array}\right]
$$

where $1 \leq 0, \ldots, \mathrm{n}-1 \leq 0$, and $\mathrm{n} \leq 0$ 


Dajcie wina i całą świnię!
give wine GEN and whole.ACC pig.ACC
'Serve some wine and a whole pig!'

In sum, the Levy/Pollard and Sag approaches are able to handle the same range of data as our approach, but we believe that the cost to the theory is high: the Levy/Pollard approach proposes additional data structures and relations that have been criticised by other HPSG researchers as too complex, while Sag proposes to abandon a fundamental tenet of the theory and move to a formal setting closer to the one that we have advocated here, allowing underspecification to handle indeterminacy. Both approaches require a special rule for coordinate structures, while our approach works within the independently-motivated treatment of coordination that is standard within LFG. We believe that the simplicity of our approach and the fact that we need no special structures or stipulations to handle particular constructions in the grammar is a strong argument in its favour.

\section{CONCLUSION AND FURTHER ISSUES}

We have outlined a new approach to syntactic indeterminacy which views the value of an indeterminate feature such as CASE as a complex and possibly underspecified feature structure. Our approach correctly allows for incremental and monotonic refinement of case requirements in particular contexts. It uses only atomic boolean-valued features (in contrast to the set values of Dalrymple \& Kaplan 2000), and requires no special mechanisms or additional assumptions in the treatment of coordination or other phenomena to handle indeterminacy (in contrast to the treatment of Ingria 1990).

In outlining the proposal here we have used a representation containing a feature for each case, but it may well be that this level of verbosity is unnecessary. We leave to future work the question of whether a more compact representation of case, perhaps based on some notion of markedness, might not be possible without loss of empirical coverage.

\footnotetext{
NP-internally, the nouns control $a c c$ and gen agreement respectively, given the token identity requirement of CASE within the noun phrase. However, given that the NP coordination rule is also equality-based, the case values of the individual conjuncts (acc and gen respectively) cause the NP schema to fail to apply, as the proposal is currently stated. An alternative which seems to solve this problem is to replace the equality-based NP coordination rule with a formulation using $\leqslant$ to relate the CAT of mother and daughters. This correctly permits the individual conjuncts to be gen and acc respectively, while the coordinate structure as a whole would be $a c c \vee g e n$. However, it is then not clear whether using the $\leqslant$ based NP coordination rule (contrary to Sag's own proposal) might not have some other undesirable consequence, given that the argumentation for the English and German patterns was predicated on the assumption of the equality-based rule for NP coordination.
} 


\section{REFERENCES}

Baerman, Matthew, Dunstan Brown \& Greville G. Corbett. 2005. The syntax-morphology interface: A study of syncretism. Cambridge: Cambridge University Press.

Bayer, Samuel. 1996. The coordination of unlike categories. Language 72, 579-616.

Blevins, James P. 2000. Markedness and agreement. Transactions of the Philological Society 98, 233-262.

Blevins, James P. 2005. Remarks on gerunds. In Orhan Orgun \& Peter Sells (eds.), Morphology and the web of grammar: Essays in memory of Steven G. Lapointe, 19-40. Stanford, CA: CSLI Publications.

Blevins, James P. To appear. Feature-based grammar. In Robert D. Borsley \& Kersti Börjars (eds.), Nontransformational syntax. Oxford: Blackwell.

Bresnan, Joan (ed.). I982. The mental representation of grammatical relations. Cambridge, MA: MIT Press.

Bresnan, Joan. 200I. Lexical-Functional Syntax. Oxford: Blackwell.

Dalrymple, Mary. 200I. Lexical Functional Grammar (Syntax and Semantics 34). New York: Academic Press.

Dalrymple, Mary \& Ronald M. Kaplan. 2000. Feature indeterminacy and feature resolution. Language 76, 759-798.

Dalrymple, Mary, Ronald M. Kaplan \& Tracy Holloway King. 2004. Linguistic generalizations over descriptions. In Miriam Butt \& Tracy Holloway King (eds.), LFGo4 Conference, 199-208. Stanford, CA: CSLI Publications. http://www-csli.stanford.edu/publications.

Dalrymple, Mary, Ronald M. Kaplan, John T. Maxwell, III \& Annie Zaenen (eds.). 1995. Formal issues in Lexical-Functional Grammar. Stanford, CA: CSLI Publications.

Daniels, Michael W. 200I. On a type-based analysis of feature neutrality and the coordination of unlikes. In Frank van Eynde, Lars Hellan \& Dorothee Beermann (eds.), HPSG 'OI Conference, I37-I47. Stanford, CA: CSLI Publications. http://csli-publications.stanford.edu/ HPSG/2/hpsgoI-toc.html.

Dyła, Stefan. 1984. Across-the-board dependencies and case in Polish. Linguistic Inquiry 15, 70I-705.

Groos, Anneke \& Henk van Riemsdijk. 1979. Matching effects in free relatives: A parameter of core grammar. In Adriana Belletti, Luciana Brandi \& Luigi Rizzi (eds.), Theory of markedness in Generative Grammar: 1979 GLOW Conference, I7I-216. Pisa: Scuola Normale Superiore di Pisa.

Ingria, Robert J. P. 1990. The limits of unification. 28th Annual Meeting of the ACL, I94-204. Pittsburgh, PA: Association for Computational Linguistics.

Jakobson, Roman. 1958. Morphological observations on Slavic declension: The structure of Russian case forms. In Russian and Slavic grammar: Studies, I93I-I98I, I05-I33. Berlin: Mouton.

Johnson, Mark \& Samuel Bayer. 1995. Features and agreement in Lambek categorial grammar. In Glyn V. Morrill \& Richard T. Oehrle (eds.), Formal grammar: The Conference of the European Summer School in Logic, Language and Information, I23-137. Barcelona: Universitat Politècnica de Catalunya.

Kaplan, Ronald M. \& Joan Bresnan. 1982. Lexical-Functional Grammar: A formal system for grammatical representation. In Bresnan (ed.), I73-28I. [Reprinted in Dalrymple et al. 1995, pp. 29-I30.]

Kaplan, Ronald M. \& John T. Maxwell, III. I988. Constituent coordination in LexicalFunctional Grammar. I2th International Conference on Computational Linguistics (COLING 88), Budapest, vol. I, 303-305. [Reprinted in Dalrymple et al. I995, pp. I99-210.]

Kaplan, Ronald M. \& Annie Zaenen. 1989. Long-distance dependencies, constituent structure, and functional uncertainty. In Mark Baltin \& Anthony Kroch (eds.), Alternative conceptions of phrase structure, 17-42. Chicago, IL: University of Chicago Press. [Reprinted in Dalrymple et al. 1995, I37-I65.]

King, Tracy Holloway. 1995. Configuring topic and focus in Russian (Dissertations in Linguistics). Stanford, CA: CSLI Publications. [Revised and corrected version of 1993 Stanford University Ph.D. dissertation.]

King, Tracy Holloway \& Mary Dalrymple. 2004. Determiner agreement and noun conjunction. Journal of Linguistics 40, 69-104. 
MARY DALRYMPLE, TRACY HOLLOWAY KING \& LOUISA SADLER

Levy, Roger. 200I. Feature indeterminacy and the coordination of unlikes in a totally well-typed HPSG. Ms., Stanford University. http://www.stanford.edu/rog/papers/feature-indet.ps.

Levy, Roger \& Carl Pollard. 200I. Coordination and neutralization in HPSG. In Frank van Eynde, Lars Hellan \& Dorothee Beermann (eds.), HPSG 'OI Conference, 22I-234. Stanford, CA: CSLI Publications. http://csli-publications.stanford.edu/HPSG/2/hpsgoI-toc.html.

Neidle, Carol. 1982. Case agreement in Russian. In Bresnan (ed.), 39I-426.

Przepiórkowski, Adam. 1999. Case assignment and the complement-adjunct dichotomy: A nonconfigurational constraint-based approach. Ph.D. dissertation, University of Tübingen.

Pullum, Geoffrey K. \& Arnold M. Zwicky. 1986. Phonological resolution of syntactic feature conflict. Language 62, 75I-773.

Sag, Ivan A. 2003. Coordination and underspecification. HPSG 'o3 Conference, 267-29I. Stanford, CA: CSLI Publications. http://www-csli.stanford.edu/publications.

Vogel, Ralf. 200I. Case conflict in German free relative constructions: An Optimality-theoretic treatment. In Geroen Müller \& Wolfgang Sternefeld (eds.), Competition in syntax, 34I-375. Berlin: Mouton de Gruyter.

Zaenen, Annie \& Lauri Karttunen. 1984. Morphological non-distinctiveness and coordination. In Gloria Alvarez, Belinda Brodie \& Terry McCoy (eds.), ESCOL '84, 309-320. Somerville, MA: Cascadilla Press.

\author{
Authors' addresses: (Dalrymple) \\ Centre for Linguistics and Philology, University of Oxford, \\ Walton St., Oxford OXI $2 H G, U K$ \\ mary.dalrymple@ling-phil.ox.ac.uk \\ (King) \\ Powerset, Inc., a Microsoft company, 475 Brannan St., \\ San Francisco, CA 94107, USA \\ tracyhollowayking@gmail.com \\ (Sadler) \\ Department of Language and Linguistics, University of Essex, \\ Wivenhoe Park, Colchester $\mathrm{CO}_{4} 3 \mathrm{SQ}, \mathrm{UK}$ \\ louisa@essex.ac.uk
}

